\title{
BMJ open In utero exposure to antidepressant drugs and risk of attention deficit hyperactivity disorder: a nationwide Danish cohort study
}

To cite: Laugesen $\mathrm{K}$, Olsen MS, Telén

Andersen $\mathrm{AB}$, et al. In utero exposure to antidepressant drugs and risk of attention deficit hyperactivity disorder: a nationwide Danish cohort study. BMJ Open 2013;3: e003507. doi:10.1136/ bmjopen-2013-003507

- Prepublication history and additional material for this paper is available online. To view these files please visit the journal online (http://dx.doi.org/10.1136/ bmjopen-2013-003507).

Received 30 June 2013 Revised 15 August 2013 Accepted 27 August 2013

Department of Clinical Epidemiology, Institute of Clinical Medicine, Aarhus University Hospital, Aarhus, Denmark

\section{Correspondence to} Kristina Laugesen; kristina. laugesen@studmed.au.dk

\section{ABSTRACT}

Objective: To investigate whether in utero exposure to antidepressants is associated with increased risk of attention deficit hyperactivity disorder (ADHD).

Design: Cohort study.

Setting: Denmark.

Participants: All Danish singletons born alive from 1996 to 2009 were included. Using national medical registries, we defined in utero exposure to antidepressants as redemption of an antidepressant prescription by the mother 30 days prior to or during pregnancy. We defined maternal former users of antidepressants as women, who had redeemed a prescription up to 30 days prior to pregnancy, and never users as women who had never redeemed a prescription.

Main outcome measures: ADHD was defined as redemption of a prescription for ADHD medication or an ADHD hospital diagnosis. Children were followed through 2010, and we used proportional-hazards regression to compute adjusted HRs comparing children exposed in utero and children born to former antidepressant users with children born to never users. To adjust for confounding from familyrelated factors, we conducted a within-mother between-pregnancy analysis comparing exposed children with unexposed siblings using conditional logistic regression.

Results: We identified a cohort of 877778 children, of whom $1.7 \%$ were exposed in utero. The overall median follow-up time was 8 years; selective serotonin reuptake inhibitors were the most commonly used class of antidepressant during pregnancy $(78 \%$ of users). The adjusted HR comparing children exposed to any antidepressant in utero with children born to never users was $1.2(95 \% \mathrm{Cl} 1.1$ to 1.4$)$, and 1.6 ( $95 \% \mathrm{Cl} 1.5$ to 1.8 ) comparing children born to former users to children born to never users of antidepressants. In the within-mother betweenpregnancy analysis $(\mathrm{n}=867)$, the adjusted $\mathrm{OR}$ was 0.7 (95\% Cl 0.4 to 1.4$)$.

Conclusions: This study provides no evidence to support a causal association between in utero exposure to antidepressants and risk of ADHD.

\section{ARTICLE SUMMARY}

Strengths and limitations of this study

- The study was based on a large study population with long and virtually complete follow-up. Our use of data from population-based databases in a setting of universal healthcare practically eliminates the risk of recall and selection biases.

- We were limited by our lack of data on actual antidepressant intake by the mother and on the actual timing of intake; we used prescription redemption as a proxy for this information, which may have biased our results towards the null hypothesis.

- Attention deficit hyperactivity disorder is a clinical diagnosis based on subjective criteria, and diagnoses therefore may vary among practitioners. Misclassification of the outcome could have led us to overestimate the association if children of mothers with a psychiatric diagnosis were more likely to obtain psychiatric treatment.

\section{INTRODUCTION}

Up to $13 \%$ of pregnant women experience depression, ${ }^{1}$ but only approximately $2 \%$ are treated with antidepressants. ${ }^{2}$ Untreated depression is associated with maternal tobacco and alcohol use, poor dietary intake and risk of poor birth outcomes, including preterm birth. ${ }^{3-6}$ However, use of selective serotonin reuptake inhibitors (SSRIs) during pregnancy has also been associated with adverse birth outcomes ${ }^{78}$ as well as teratogenic effects. ${ }^{9} 10$

Early-life exposure to SSRIs or tricyclic antidepressive agents may cause behavioural changes, as observed in rodents. ${ }^{11} 12$ The serotonin transporter, which is blocked by SSRIs, is expressed transiently in many brain areas during fetal life; serotonin plays a key role in neural development and maturation. ${ }^{13}$ Attention deficit hyperactivity disorder 
(ADHD) is a common neurodevelopmental disorder characterised by impulsiveness, inattention and hyperactivity. ${ }^{14}$ The incidence of ADHD is increasing, with a current prevalence of approximately 5\% in children. ${ }^{15}$ Proposed risk factors include genetics, preterm birth and prenatal exposure to smoking or maternal stress. ${ }^{16-20}$ However, evidence about risk of ADHD following in utero exposure to antidepressants is limited to one study, which found no evidence for an association between in utero exposure to SSRIs and ADHD (OR: 0.91, 95\% CI 0.51 to 1.60$){ }^{21}$

Evidence of an association between antidepressant use during pregnancy and later ADHD in the offspring would have major public health implications. In this study, we investigated whether in utero exposure to antidepressants was associated with an increased risk of ADHD using nationwide Danish medical registries with virtually complete long-term follow-up.

\section{METHODS}

Setting

The Danish healthcare system (5.5 million inhabitants and a yearly birth rate of approximately 65000 ) provides tax-supported health services to all residents guaranteeing access to primary and secondary care free of charge. Except for emergencies, initial contact with the healthcare system is through general practitioners, who either treat patients themselves or refer them to hospitals or to private practice specialists.

\section{Study population and design}

Using the Danish Medical Birth Registry, we identified a cohort of all singletons born alive from 1996 until the end of 2009. The Danish Medical Birth Registry contains computerised records of all deliveries in Denmark since 1973. Each record includes the civil registration number of the mother, father and newborn, as well as multiple variables regarding the delivery, the newborn and the mother. Data are collected by midwives or physicians overseeing delivery. ${ }^{22}$ The civil registration number is a 10-digit number assigned to each Danish citizen at birth and to residents on immigration, enabling accurate and unambiguous linkage of relevant registries at the individual level. ${ }^{23}$ Siblings born to the same mother were identified through the civil registration system. ${ }^{23}$ Thus, in addition to a general population comparison cohort, it was possible to identify a sibling comparison cohort that was highly suitable for optimising adjustment for important potential family-related and genetic confounders.

\section{Maternal antidepressant use}

In utero exposure to antidepressants was defined as maternal redemption of a prescription for an antidepressant 30 days prior to or during pregnancy, as identified through the Danish National Prescription Registry. ${ }^{24}$ Since January 1994, the registry has recorded the following information whenever a prescription is redeemed in Denmark: the civil registration number of the patient, the medication classification code (the anatomical therapeutic chemical classification system of the $\mathrm{WHO}$ ) and the date of dispensing. All antidepressants, as well as drugs for ADHD, are available by prescription only in Denmark. Pregnancy was defined as starting from the first day in the last menstrual period, according to the Danish Medical Birth Registry. First-trimester exposure was defined as redemption of a prescription by the mother 30 days prior to the beginning of pregnancy and up to 12 weeks after the beginning of pregnancy; second-trimester exposure was defined as prescription redemption between 12 weeks and 28 weeks of pregnancy and third-trimester exposure was defined as prescription redemption during the remainder of the pregnancy. ${ }^{25}$ If the mother redeemed more than one prescription during pregnancy, the first redemption was used to determine the trimester of exposure. We defined maternal former users of antidepressants as women, who had redeemed a prescription up to 30 days prior to pregnancy, and never users as women who had never redeemed a prescription.

\section{Attention deficit hyperactivity disorder}

ADHD was detected either as a diagnosis of ADHD or redemption of a prescription for ADHD medication. Using the Danish Psychiatric Registry ${ }^{26}$ and the Danish National Registry of Patients, ${ }^{27}$ we identified children in the study population with inpatient and outpatient hospital diagnoses of ADHD. The Danish Psychiatric Registry contains computerised data on all admissions to psychiatric hospitals and psychiatric wards in Denmark. The Danish National Registry of Patients has tracked all inpatient stays in Danish hospitals since 1977, and outpatient clinic and emergency room visits at all public hospitals since 1995. Data recorded in the Danish National Registry of Patients and the Danish Psychiatric Registry include civil registration number of the patient, dates of admission and discharge and up to 20 discharge diagnoses from each admission, classified according to the 8th revision of the International Classification of Diseases until 1993, and the 10th revision thereafter.

Diagnosing and treating ADHD is also handled by private practice psychiatrists and general practitioners in cooperation, without hospital contact. These patients are not recorded in the Danish Psychiatric Registry or the Danish National Registry of Patients. Therefore, to ensure completeness, we defined ADHD as either a diagnosis of ADHD or a redemption of a prescription for ADHD medication. Information on prescription redemption was obtained from the Danish National Prescription Registry. ${ }^{24}$

\section{Covariates}

Risk factors for ADHD that were potentially associated with maternal use of antidepressants were identified. We obtained information on maternal and paternal psychiatric diagnoses anytime before baseline from the Danish Psychiatric Registry. Information was also gathered on 
maternal epilepsy, infections and use of anxiolytics/hypnotics/sedatives during pregnancy from the Danish National Registry of Patients and the Danish National Prescription Registry. From the Danish Medical Birth Registry we obtained information on maternal age at birth, gender of the child, the child's birth order, maternal smoking during pregnancy, maternal body mass index and marital status. As body mass index was only available starting in 2004 and marital status was incompletely registered, body mass index and marital status were only included as potential confounders in separate subanalyses. We also obtained information on the child's gestational age, birth weight and 5-min Apgar score from the Danish Medical Birth Registry. These variables were investigated because they may play a role in a causal pathway linking in utero antidepressant exposure and ADHD. Since antidepressant use and ADHD prevalence increased between 1996 and 2010, we also adjusted for calendar time.

\section{Statistical analyses}

The children were followed from date of birth until the date of redemption of an ADHD prescription, receipt of an ADHD diagnosis, emigration, death or the end of follow-up on 31 December 2010, whichever came first.

\section{General population comparison cohort}

We compared children exposed to antidepressants in utero and also children of maternal former users with the unexposed children of never users (women who never redeemed a prescription for antidepressants). We performed separate analyses according to type of antidepressant (SSRIs, serotonin-norepinephrine reuptake inhibitors, tricyclic antidepressive agents, other antidepressants and combinations of antidepressants). For these subgroups, we conducted analyses comparing exposed children to unexposed children of never users. With Cox proportional-hazards regression, we computed crude and adjusted HRs (aHR) with 95\% CIs as measures of relative risk. Patients with missing data were excluded from the analyses. The assumption of proportional hazards was graphically verified.

\section{Sibling comparison cohort}

To optimise control for family-related factors, such as genetics and socioeconomic or medical status, we conducted a within-mother between-pregnancy cohort analysis by restricting the study population to children of mothers who had more than one child and at least one exposed and one unexposed pregnancy. We then compared exposed children to unexposed children using a conditional logistic regression model. We computed adjusted ORs (aOR) with 95\% CIs for receiving an ADHD diagnosis or redeeming a prescription for ADHD medication. In the first model, we adjusted for calendar time at birth to account for differences in length of follow-up. In this way we were able to compare the sibling analysis with the time-to-event analysis used in the general population comparison cohort. ${ }^{28}$ A stratified Cox proportional-hazards regression showed the same results as the conditional logistic regression model. The second model was fully adjusted. All statistical analyses were performed using SAS (V.9.2; SAS Institute Inc, Cary, North Carolina, USA). This study was approved by the Danish Data Protection Agency (Record no. 2013-41-1790). Codes used to define study variables are provided in the online supplementary appendices.

\section{RESULTS}

We identified 877778 singletons, of whom 15008 $(1.7 \%)$ were exposed to antidepressants in utero (tables 1 and 2). The most commonly used class of antidepressant by the mothers was SSRIs (78\%, table 3). The overall median follow-up time was 8 years. A total of $12841(1.5 \%)$ participants who developed ADHD (8100 $(0.9 \%)$ were detected as a diagnosis of $\mathrm{ADHD}$, and 4741 $(0.5 \%)$ were identified through redemption of a prescription for ADHD medication as a first-outcome measure). In the within-mother between-pregnancy analysis we identified 867 children (330 groups of siblings) of whom $348(40 \%)$ were exposed to antidepressants in utero. Of the 348 exposed children, 79 (23\%) developed ADHD. Of the 519 unexposed children, $270 \quad(52 \%)$ developed ADHD. Of 330 groups of siblings, 311 groups contained one child with ADHD and 19 pairs contained two children with ADHD.

\section{Maternal and paternal characteristics}

Age at delivery was higher among antidepressant users than never users. Maternal antidepressant users more frequently smoked during pregnancy, were unmarried, had psychiatric diagnoses other than depression, epilepsy or infections during pregnancy. They also used anxiolytics/hypnotics/sedatives during pregnancy more often than never users. Fathers of children born to maternal users of antidepressants were also more likely to have a psychiatric diagnosis than fathers of children born to never users (table 1 ).

\section{Birth outcomes}

Gender distribution was the same for exposed and unexposed children. Children exposed in utero to antidepressants had a higher prevalence of low birthweight (3.7\% vs $2.1 \%)$, low Apgar score (seven or under) at $5 \mathrm{~min}(2.6 \%$ vs $1.2 \%)$ and were born prematurely more often $(15.4 \%$ vs $8.6 \%)$ than unexposed children born by never users (table 2).

\section{Risk estimates}

The aHR comparing children exposed to any antidepressant in utero with children born to never users was $1.2(95 \%$ CI 1.1 to 1.4 ; table 4$)$. The aHR was 1.6 (95\% CI 1.5 to 1.8$)$ when comparing children born to former users of antidepressants with children born to never users. Adjusting for the mother's body mass index 
Table 1 Maternal and paternal characteristics of 877778 singleton births in Denmark in 1996-2009, according to maternal use of antidepressants during pregnancy

\begin{tabular}{|c|c|c|c|c|}
\hline Characteristic & $\begin{array}{l}\text { Exposed in } \\
\text { utero, } n(\%)\end{array}$ & $\begin{array}{l}\text { Not exposed in utero } \\
\text { and born to former } \\
\text { users, } n(\%)\end{array}$ & $\begin{array}{l}\text { Not exposed in utero } \\
\text { and born to never } \\
\text { users, } n(\%)\end{array}$ & Total, n (\%) \\
\hline All births & $15008(100)$ & $45978(100)$ & $816792(100)$ & $877778(100)$ \\
\hline \multicolumn{5}{|l|}{ Mother's age at birth } \\
\hline 24 years of age or less & 2206 (14.7) & $5340(11.6)$ & 114203 (14.0) & $121749(13.9)$ \\
\hline $25-29$ years of age & 4449 (29.6) & $14146(30.8)$ & 286404 (35.1) & 304999 (34.7) \\
\hline $30-34$ years of age & 5048 (33.6) & $16318(35.5)$ & 287344 (35.2) & 308710 (35.2) \\
\hline $35-39$ years of age & 2731 (18.2) & 8377 (18.2) & 111166 (13.6) & $122274(14.0)$ \\
\hline 40 years of age or more & $574(3.8)$ & 1797 (3.9) & $17675(2.2)$ & $20046(2.3)$ \\
\hline \multicolumn{5}{|l|}{ Birth order } \\
\hline First child & $6417(42.8)$ & $18745(40.8)$ & 351959 (43.1) & $377121(43.0)$ \\
\hline Second or later child & 8591 (57.2) & 27233 (59.2) & $464833(57.0)$ & 500657 (57.0) \\
\hline \multicolumn{5}{|l|}{ Smoking status } \\
\hline Non-smoker & 9424 (62.8) & 31797 (69.2) & $637561(78.1)$ & $678782(77.3)$ \\
\hline Smoker & $5033(33.5)$ & $12707(27.6)$ & $148094(18.1)$ & 165834 (18.9) \\
\hline Missing data & $551(3.7)$ & $1474(3.2)$ & $31137(3.8)$ & $33162(3.8)$ \\
\hline \multicolumn{5}{|l|}{ Marital status } \\
\hline Married, civil partnership & $4049(27.0)$ & $13164(28.6)$ & 360924 (44.2) & $378137(43.1)$ \\
\hline $\begin{array}{l}\text { Single, widow, divorced or not } \\
\text { registered/ annulled civil partner ship }\end{array}$ & $4840(32.2)$ & $14280(31.1)$ & $295762(36.2)$ & $314882(35.9)$ \\
\hline Missing or partner dead & $6119(40.8)$ & $18534(40.3)$ & $160106(19.6)$ & $184759(21.0)$ \\
\hline Maternal diagnosis of depression & $3987(26.6)$ & $5176(11.3)$ & $2064(0.3)$ & $11227(1.3)$ \\
\hline $\begin{array}{l}\text { Maternal psychiatric diagnoses other than } \\
\text { depression }\end{array}$ & $4136(27.6)$ & $8659(18.8)$ & $28247(3.5)$ & $41042(4.7)$ \\
\hline Paternal psychiatric diagnoses & $1823(12.1)$ & 4700 (10.2) & $45471(5.6)$ & $51994(5.9)$ \\
\hline Maternal diseases & $6998(46.6)$ & 20298 (44.2) & 276823 (33.9) & $304199(34.7)$ \\
\hline Epilepsy & $315(2.1)$ & $909(2.0)$ & $8313(1.0)$ & $9537(1.1)$ \\
\hline Infections during pregnancy & $6838(45.6)$ & $19829(43.1)$ & 271789 (33.3) & $298456(34.0)$ \\
\hline $\begin{array}{l}\text { Maternal medication use during pregnancy } \\
\text { anxiolytics/hypnotives/sedatives }\end{array}$ & $1764(11.8)$ & $1354(2.9)$ & $5137(0.6)$ & $8255(0.9)$ \\
\hline \multicolumn{5}{|l|}{ Maternal body mass index (BMI) } \\
\hline No BMI (before 2004) & 4681 (31.2) & $13748(29.9)$ & $489283(60.0)$ & $507712(57.8)$ \\
\hline Underweight (BMI 15-18.4 kg/m²) & $537(3.6)$ & $1788(3.9)$ & $15082(1.8)$ & 17407 (2.0) \\
\hline Normal weight (BMI $\left.18.5-24.9 \mathrm{~kg} / \mathrm{m}^{2}\right)$ & $5217(34.8)$ & $17452(38.0)$ & $190466(23.3)$ & $213135(24.3)$ \\
\hline Overweight (BMI $25-29.9 \mathrm{~kg} / \mathrm{m}^{2}$ ) & $2166(14.4)$ & $6332(13.8)$ & $63044(7.7)$ & $71542(8.2)$ \\
\hline Obese $\left(\mathrm{BMl} \geq 30 \mathrm{~kg} / \mathrm{m}^{2}\right)$ & 1635 (10.9) & $4244(9.2)$ & $34052(4.2)$ & $39931(4.6)$ \\
\hline $\mathrm{BMl}<15 \mathrm{~kg} / \mathrm{m}^{2}$ or missing & $772(5.1)$ & $2414(5.3)$ & $24865(3.0)$ & 28051 (3.2) \\
\hline
\end{tabular}

and marital status in subanalyses did not change the estimates (results not shown). When stratifying according to trimester and class of antidepressants, we detected a minor association between ADHD and exposure in utero to any kind of antidepressant in the first and second trimesters, as well as exposure to SSRIs or the group 'other antidepressants' (table 4). In the withinmother between-pregnancy analysis, the full aOR was 0.7 (95\% CI 0.4 to 1.4 ; table 5$)$.

\section{DISCUSSION}

While our analyses based on a general population comparison cohort showed a weak association between in utero exposure to antidepressants and ADHD, the within-mother between-pregnancy analyses were not consistent with a causal association. This observation strongly indicates the presence of unmeasured confounding by family-related factors in our comparisons with the general population. The former user analysis in the general comparison cohort also confirmed the presence of unmeasured confounding factors.

Our results extend the findings of an American study of claims-based data from 38074 families that concluded, in line with our findings, that children exposed to SSRIs were not at increased risk of ADHD (OR: 0.91, 95\% CI 0.51 to 1.60 ) while children exposed to bupropion were at increased risk (OR: $3.63,95 \%$ CI 1.20 to 11.04 ), especially after second-trimester exposure. ${ }^{21}$ The study was limited by maternal smoking during pregnancy as a potential confounder, especially in the results for exposure to bupropion as this antidepressant is used for smoking cessation. 
Table 2 Characteristics of 877778 singleton births in Denmark in 1996-2009, according to maternal use of antidepressants during pregnancy

\begin{tabular}{|c|c|c|c|c|}
\hline Characteristic & $\begin{array}{l}\text { Exposed in } \\
\text { utero, } \mathrm{n}(\%)\end{array}$ & $\begin{array}{l}\text { Not exposed } \\
\text { in utero and } \\
\text { born to former } \\
\text { users, } \mathrm{n}(\%)\end{array}$ & $\begin{array}{l}\text { Not exposed } \\
\text { in utero and } \\
\text { born to never } \\
\text { users, } n(\%)\end{array}$ & Total n (\%) \\
\hline \multicolumn{5}{|l|}{ Gender of the child } \\
\hline Female & 7233 (48.2) & 22216 (48.3) & 397731 (48.7) & $427180(48.7)$ \\
\hline Male & 7775 (51.8) & $23762(51.7)$ & 419061 (51.3) & $450598(51.3)$ \\
\hline \multicolumn{5}{|l|}{ Calendar period of birth } \\
\hline 1996-2000 & 2000 (13.3) & $5542(12.1)$ & 314467 (38.5) & $322009(36.7)$ \\
\hline 2001-2005 & 5294 (35.3) & 16706 (36.3) & 287077 (35.1) & 309077 (35.2) \\
\hline 2006-2009 & $7714(51.4)$ & 23730 (51.6) & $215248(26.4)$ & $246692(28.1)$ \\
\hline \multicolumn{5}{|l|}{ Birth weight in grams } \\
\hline 1500-1999 & $163(1.1)$ & $418(0.9)$ & $5629(0.7)$ & $6210(0.7)$ \\
\hline 2000-2499 & 549 (3.7) & $1259(2.7)$ & $17444(2.1)$ & $19252(2.2)$ \\
\hline 2500-2999 & $2164(14.4)$ & $5511(12.0)$ & $81730(10.0)$ & 89405 (10.2) \\
\hline $3000-5500$ & $11924(79.5)$ & 38189 (83.1) & $700553(85.8)$ & $750666(85.5)$ \\
\hline Very low, very high or missing & $208(1.4)$ & $601(1.3)$ & $11436(1.4)$ & $12245(1.4)$ \\
\hline \multicolumn{5}{|l|}{ Gestational age } \\
\hline Extremely premature or very premature, 19-31 weeks & $150(1.0)$ & $388(0.8)$ & $5193(0.6)$ & $5731(0.7)$ \\
\hline Moderately premature, $32-37$ weeks & 2303 (15.3) & $5140(11.2)$ & $70517(8.6)$ & 77960 (8.9) \\
\hline Normal gestational age at birth, 38-48 weeks & $12482(83.2)$ & $40272(87.6)$ & $735496(90.0)$ & $788250(89.8)$ \\
\hline Too low or missing gestational age at birth & $73(0.5)$ & $178(0.4)$ & $5586(0.7)$ & $5837(0.7)$ \\
\hline \multicolumn{5}{|l|}{ Apgar score at 5 min } \\
\hline Apgar score seven or under & $385(2.6)$ & $610(1.3)$ & $10135(1.2)$ & $11130(1.3)$ \\
\hline Apgar score over seven & $14463(96.4)$ & $44938(97.7)$ & $796921(97.6)$ & $856322(97.6)$ \\
\hline Missing & $160(1.1)$ & $430(0.9)$ & $9736(1.2)$ & $10326(1.2)$ \\
\hline
\end{tabular}

Bupropion (which in Denmark is used for smoking cessation only) was contained in the group 'other' antidepressants in our study. The number of children exposed to this drug in utero was only 135 and due to sparse data we did not perform separate regression analyses.

The strengths of our study include its large study population with long and virtually complete follow-up. Our use of data from population-based databases in a setting of universal healthcare practically eliminates the risk of recall and selection biases. Importantly, the within-mother between-pregnancy analysis allowed us to effectively adjust for family-related factors, such as genetics and socioeconomic and medical status.

Table 3 Distribution of 15008 maternal antidepressants users according to classes of antidepressants

\begin{tabular}{lc}
\hline Class of antidepressant & $\begin{array}{l}\text { Maternal } \\
\text { users (\%) }\end{array}$ \\
\hline Selective serotonin reuptake inhibitors & $11721(78)$ \\
Serotonin-norepinephrine reuptake & $763(5)$ \\
inhibitors & \\
Tricyclic antidepressive agents & $716(5)$ \\
Other & $604(4)$ \\
Combined & $1204(8)$ \\
Total & $15008(100)$ \\
\hline
\end{tabular}

We were limited by our lack of data on actual antidepressant intake by the mother and on the actual timing of intake. We used prescription redemption as a proxy for this information which could lead to misclassification of exposure status. Regarding children classified as exposed in utero, we cannot be sure that women who redeemed a prescription 30 days before or during pregnancy actually used the drugs during pregnancy. Also, drugs redeemed earlier in life could have been stored for later use. Therefore, women categorised as former users might have been using antidepressants during pregnancy. Furthermore, the Danish National Prescription Registry ${ }^{24}$ has only recorded information since 1994. Among women who were categorised as never users some may have used the drugs before 1994. Such misclassification of exposure may have biased our result towards the null. Also, $\mathrm{ADHD}$ is a clinical diagnosis based on subjective criteria, and diagnoses may vary among practitioners. Misclassification could have led us to overestimate the association if children of mothers with a psychiatric diagnosis were more likely to obtain psychiatric treatment. At the same time, children with ADHD were identified based on hospital diagnoses and drug prescriptions. Thus, patients with ADHD diagnosed by private psychiatrists or general practitioners and not prescribed drug treatment would be misclassified 
Table 4 Crude and adjusted HRs and $95 \%$ Cls for time to redeem a prescription for attention deficit hyperactivity disorder (ADHD) medication or receiving the diagnosis of ADHD, comparing exposed children to unexposed children born to never users (women who had never redeemed a prescription on antidepressants)

\section{Antidepressant drug exposure in utero}

Any

First-trimester exposure

Second-trimester exposure

Third-trimester exposure

Selective serotonin reuptake inhibitor

Serotonin-norepinephrine reuptake inhibitor

Tricyclic antidepressive agent

Others

Combined use

Crude HR and $(95 \% \mathrm{Cl})$

2.0 (1.7 to 2.3$)$

2.0 (1.7 to 2.3$)$

2.6 (1.7 to 4.2$)$

$1.3(0.6$ to 3.2$)$

2.1 (1.8 to 2.4$)$

$1.2(0.5$ to 3.3$)$

1.8 (1.1 to 3.0$)$

2.4 (1.3 to 4.4$)$

$1.9(1.1$ to 3.4$)$
Adjusted* HR and $(95 \% \mathrm{Cl})$

$1.2(1.1$ to 1.4$)$

$1.2(1.0$ to 1.4$)$

1.5 (0.9 to 2.4$)$

$0.8(0.3$ to 2.0$)$

$1.2(1.0$ to 1.5$)$

$1.0(0.4$ to 2.5$)$

$1.1(0.6$ to 2.0$)$

$1.6(0.8$ to 3.0$)$

$0.8(0.4$ to 1.7$)$

${ }^{*}$ Adjusted for gender of the child, calendar time at birth, birth order, maternal age at birth, maternal smoking status, maternal psychiatric diagnoses, paternal psychiatric diagnoses, maternal diseases during pregnancy (infections, epilepsy) and maternal medication (anxiolytics/ hypnotics/sedatives) use during pregnancy.

as not having ADHD. This could lead to an underestimation of the association. The within-mother between-pregnancy analysis also may be limited by misclassification of exposure status and outcome. Such misclassification may have led us to underestimate an association in this analysis. ${ }^{29}$ However, the strong association between former maternal antidepressant use and ADHD in offspring, compared with a lack of exposure to antidepressants in utero, further supports the importance of causative factors other than antidepressant use. Comorbid ADHD in mothers using antidepressants would potentially conceal a causal association between in utero exposure to antidepressants and ADHD, given the strong ADHD risk conveyed by parental ADHD. However, given the reported prevalence of ADHD among adults with major depression, ranging from $6 \%$ to $9 \%^{30}$ we do not believe parental ADHD can explain the null association.

In conclusion, this large-scale study with complete long-term follow-up for ADHD provides no evidence to support an association between in utero exposure to antidepressants and risk of ADHD.

Table 5 Adjusted ORs and 95\% Cls for a within-mother between-pregnancy analysis on a subpopulation of 867 children, restricted to mothers who had more than one child, with at least one exposed and at least one unexposed pregnancy

\begin{tabular}{ll}
\hline Adjusted* OR $(95 \% \mathrm{Cl})$ & Adjusted† OR $(95 \% \mathrm{Cl})$ \\
\hline $0.8(0.5$ to 1.2$)$ & $0.7(0.4$ to 1.4$)$ \\
\hline
\end{tabular}

Children exposed in utero are compared with unexposed children. *Adjusted for calendar time at birth.

†Adjusted for calendar time at birth, gender of the child, birth order, maternal age at birth, maternal smoking status, materna psychiatric diagnoses, paternal psychiatric diagnoses, maternal diseases during pregnancy (infections and epilepsy) and maternal medicine use (anxiolytics/hypnotics/sedatives) during pregnancy.
Acknowledgements We would like to thank all participants in this study.

Contributors $\mathrm{KL}, \mathrm{MSO}, \mathrm{ABTA}$ and HTS made primary contributions to writing the article. All authors contributed to the study conception and study design. TF performed data collection and statistical analyses and commented on the article. All authors contributed to the interpretation of results and revising the article critically and all approved the final article. HTS is the guarantor for this study.

Funding This study was supported by grants from 'Max og Anna Friedmanns Legat til Sygdomsbekæmpelse', 'Familien Hede Nielsens Fond' and from the Department of Clinical Epidemiology's Research Foundation. Research was conducted independently of the funders. Department of Clinical Epidemiology, Aarhus University Hospital, receives funding for other studies from companies in the form of research grants to (and administered by) Aarhus University. None of these studies have any relation to the current study.

\section{Competing interests None.}

Ethics approval Register studies do not require ethical approval in Denmark. This study was approved by the Danish Data Protection Agency (Record no. 2013-41-1790).

Provenance and peer review Not commissioned; externally peer reviewed. Data sharing statement No additional data are available.

Open Access This is an Open Access article distributed in accordance with the Creative Commons Attribution Non Commercial (CC BY-NC 3.0) license, which permits others to distribute, remix, adapt, build upon this work noncommercially, and license their derivative works on different terms, provided the original work is properly cited and the use is non-commercial. See: http:// creativecommons.org/licenses/by-nc/3.0/

\section{REFERENCES}

1. Bennett HA, Einarson A, Taddio A, et al. Prevalence of depression during pregnancy: systematic review. Obstet Gynecol 2004;103:698-709.

2. http://www.sst.dk/Nyhedscenter/Nyheder/2007/nye_tal_20-07.aspx (accessed 29 Mar 2013)

3. Bennett HA, Einarson A, Taddio A, et al. Depression during pregnancy: overview of clinical factors. Clin Drug Invest 2004;24:157-79.

4. Pajulo M, Savonlahti E, Sourander A, et al. Antenatal depression, substance dependency and social support. J Affect Disord 2001;65:9-17.

5. Zuckerman $\mathrm{B}$, Amaro $\mathrm{H}$, Baucher $\mathrm{H}$, et al. Depressive symptoms during pregnancy: relationship to poor health behaviours. $A m J$ Obstet Gynecol 1989;160:1107-11.

6. Grote NK, Bridge JA, Gavin AR, et al. A meta-analysis of depression during pregnancy and the risk of preterm birth, low birth weight, and intrauterine growth restriction. Arch Gen Psychiatry 2010;67:1012-24. 
7. Chambers CD, Johnson KA, Dick LM, et al. Birth outcomes in pregnant women taking fluoxetine. $N$ Engl J Med 1996;335:1010-15.

8. Wen SW, Yang Q, Garner $P$, et al. Selective serotonin reuptake inhibitors and adverse pregnancy outcomes. Am J Obstet Gynecol 2006;194:961-6.

9. Pedersen LH, Henriksen TB, Vestergaard M, et al. Selective serotonin reuptake inhibitors in pregnancy and congenital malformations: population based cohort study. BMJ 2009;339:b3569.

10. Chambers CD, Hernandez-Diaz S, Van Marter LJ, et al. Selective serotonin-reuptake inhibitors and risk of persistent pulmonary hypertension of the newborn. N Engl J Med 2006;354:579-87.

11. Coleman FH, Christensen HD, Gonzalez CL, et al. Behavioral changes in developing mice after prenatal exposure to paroxetine (Paxil). Am J Obstet Gynecol 1999;181:1166-71.

12. Maciag D, Simpson KL, Coppinger D, et al. Neonatal antidepressant exposure has lasting effects on behavior and serotonin circuitry. Neuropsychopharmacology 2006;31:47-57.

13. Homberg JR, Schubert D, Caspar P. New perspectives on the neurodevelopmental effects of the SSRIs. Trends Pharmacol Sci 2010;31:60-5.

14. WYD P. 2000. http://www.adhd.org.nz/ICD101.html (accessed 15 Feb 2013).

15. Polanczyk G, de Lima MS, Horta BL, et al. The worldwide prevalence of ADHD: a systematic review and metaregression analysis. Am J Psychiatry 2007;164:942-8.

16. Chu SM, Tsai MH, Hwang FM, et al. The relationship between attention deficit hyperactivity disorder and premature infants in Taiwanese: a case control study. BMC Psychiatry 2012;12:85.

17. Polanska K, Jurewicz J, Hanke W. Exposure to environmental and lifestyle factors and attention-deficit/hyperactivity disorder in children-a review of epidemiological studies. Int J Occup Med Environ Health 2012;25:330-55.
18. Faraone SV, Perlis $\mathrm{RH}$, Doyle AE, et al. Molecular genetics of attention-deficit/hyperactivity disorder. Biol Psychiatry 2005;57:1313-23.

19. Swanson JM, Kinsbourne M, Nigg J, et al. Etiologic subtypes of attention-deficit/hyperactivity disorder: brain imaging, molecular genetic and environmental factors and the dopamine hypothesis. Neuropsychol Rev 2007;17:39-59.

20. Linnet KM, Dalsgaard S, Obel C, et al. Maternal lifestyle factors in pregnancy risk of attention deficit hyperactivity disorder and associated behaviors: review of the current evidence. Am J Psychiatry 2003;160:1028-40.

21. Figueroa R. Use of antidepressants during pregnancy and risk of attention-deficit/hyperactivity disorder in offspring. J Dev Behav Pediatr 2010;31:641-8.

22. Knudsen LB, Olsen J. The Danish Medical Birth Registry. Dan Med Bull 1998;45:320-3.

23. Pedersen CB. The Danish Civil Registration System. Scand J Public Health 2011;39:22-5.

24. Kildemoes HW, Sørensen HT, Hallas J. The Danish National Prescription Registry. Scand J Public Health 2011;39:38-41.

25. http://medical-dictionary.thefreedictionary.com/trimester (accessed 31 Mar 2013)

26. Mors O, Perto GP, Mortensen PB. The Danish Psychiatric Central Research Register. Scand J Public Health 2011;39:54-7.

27. Andersen TF, Madsen M, Jorgensen J, et al. The Danish National Hospital Register. A valuable source of data for modern health sciences. Dan Med Bull 1999;46:263-8.

28. Cox DR. Regression models and life tables (with discussion). J R Stat Soc 1972;34:187-220.

29. Frisell T, Öberg S, Kuja-Halkola R, et al. Sibling comparison designs: bias from non-shared confounders and measurement error. Epidemiology 2012;23:713-20.

30. Mclntosh D, Kutcher S, Binder C, et al. Adult ADHD and comorbid depression: a consensus-derived algorithm for ADHD. Neuropsychiatry Dis Treat 2009;5:137-50. 